\title{
SEQUÊNCIAS DIDÁTICAS E PRÁTICAS PEDAGÓGICAS EM CIÊNCIAS NATURAIS: ELEMENTOS EMERGENTES DE PESQUISAS CONTEMPORÂNEAS
}

\section{Teaching sequences and pedagogical practices in Natural Sciences: emergent elements of contemporary research}

Carlos Ventura Fonseca ${ }^{1}$

Fernanda Bianca Hesse ${ }^{2}$

\begin{abstract}
Resumo: Este artigo apresenta uma revisão acerca da produção acadêmica publicada nas atas do Encontro Nacional de Pesquisa em Educação em Ciências, pelo período que compreende os anos 2010 até 2020, especificamente relacionada a trabalhos que envolvem os tópicos sequências didáticas e práticas pedagógicas. A pesquisa foi desenvolvida a partir de sete procedimentos distintos, compreendendo a utilização de algumas palavras-chave para busca, havendo realização posterior de análise de conteúdo dos textos selecionados. Os resultados revelam que os autores, de forma majoritária, atuam coletivamente e são vinculados a universidades públicas da região sudeste do Brasil. As práticas pedagógicas constatadas na amostra, em maior proporção: são destinadas ao ensino de Ciências Naturais no âmbito do Ensino Médio e dos anos finais do Ensino Fundamental; abrangem aulas expositivas e dialogadas/ atividades investigativas; orientam-se pelo modelo pedagógico construtivista, privilegiando conteúdos conceituais e procedimentais em seus processos avaliativos, bem como utilizando temas contextuais como forma de organização do trabalho a ser desenvolvido na sala de aula. Como desafios inerentes à área de Didática das Ciências, no Brasil, evidencia-se a necessidade: de maior visibilidade e ocorrência de pesquisas envolvendo práticas pedagógicas voltadas aos anos iniciais do Ensino Fundamental e à Educação Infantil; de maior participação de professores, atuantes em escolas de Educação Básica, na autoria de trabalhos da literatura especializada; de maior valorização e disseminação de abordagens pedagógicas que contemplem a perspectiva centrada no modelo pedagógico sociocultural.
\end{abstract}

Palavras-chave: Didática das Ciências. Revisão da literatura. Práticas pedagógicas.

Abstract: This article presents a review of the academic production published in the minutes of the National Meeting of Research in Science Education, for the period from 2010 to 2020, specifically related to works involving the topics of teaching sequences and pedagogical practices. The research was developed from seven different procedures, comprising the use of some keywords for the search, with subsequent content analysis of the selected texts. The results reveal that the majority of the authors work collectively and are linked to public universities in

\footnotetext{
${ }^{1}$ Doutor em Educação (2014) e Professor da Universidade Federal do Rio Grande do Sul (UFRGS), sendo vinculado ao Departamento de Ensino e Currículo (DEC) da Faculdade de Educação (FACED). ORCID: https://orcid.org/0000-0002-7464-0065.E-mail: carlos.fonseca@ufrgs.br.

2 Bacharela em Química pela Universidade LASALLE (2014). Estudante da UFRGS no curso de Licenciatura em Química (desde 2017). Atua como bolsista de iniciação científica. ORCID: https://orcid.org/0000-0003-32229873. E-mail: fehesse@ hotmail.com.
} 
the southeast region of Brazil. The pedagogical practices found in the sample in greater proportion are aimed at teaching Natural Sciences in High School and the final years of Elementary School; cover expository and dialogued classes/investigative activities; they are guided by the constructivist pedagogical model, privileging conceptual and procedural content in their evaluation processes, as well as using contextual themes as a way of organizing the work to be developed in the classroom. As challenges inherent to the area of Didactics of Natural Sciences in Brazil, the highlighted need is for greater visibility and occurrence of research involving pedagogical practices aimed at the early years of Elementary School and Early Childhood Education; for greater participation of teachers, working in Basic Education schools, in the authorship of specialized literature articles; for greater appreciation and dissemination of pedagogical approaches that contemplate the perspective centered on the sociocultural pedagogical model.

Keywords: Didactics of Natural Sciences. Literature revision. Pedagogical practices.

\section{Introdução}

Este artigo, partindo da perspectiva de Veiga (2012), entende que os procedimentos didáticos buscam responder às necessidades atreladas ao ensino e à aprendizagem, sendo que o ato de ensinar requer: intencionalidade (possui certos objetivos, tem compromissos com teorias da aprendizagem e perspectivas filosóficas), interação (compartilhamento, diálogo com outros seres humanos), expressão de afetividade (o convívio deve resultar no bem-estar dos envolvidos), movimentos de construção do conhecimento e rigor no desenvolvimento de metodologias (conexões do conhecimento com as práticas sociais, estratégias didáticas convergentes com os objetivos propostos e acompanhamento avaliativo dos processos) e planejamento (ação que não é linear e/ou meramente técnica, mas que evita o improviso e possibilita organização do trabalho, buscando identificar: por que, para que, para quem, como, onde e quando ensinar). A autora mencionada entende o ensino como prática social crítica que, considerando-se as questões sociais que circundam o ambiente educacional escolar, propõe "caminhos alternativos para o desenvolvimento dos temas" e "exige preparo, compromisso e responsabilidade do professor para instrumentalizar política e tecnicamente o aluno, ajudando a constituir-se como sujeito social" (VEIGA, 2012, p. 29).

O posicionamento epistemológico deste trabalho também se coloca na linha de abordagem teórica que entende o magistério como um campo de atuação a ser fortalecido, na contemporaneidade, o que converge com o entendimento de que se deve superar a visão ingênua e pouco estruturada sobre os saberes profissionais específicos, sendo esta alicerçada fragilmente no conhecer a matéria, no julgar as situações pelo "bom senso", "na experiência, na intuição, no talento ou numa vasta cultura" (GAUTHIER et al., 2013, p. 28). Segundo os autores citados, há um compêndio de saberes profissionais os quais são fonte contínua de abastecimento para o trabalho do professor, quais sejam: saberes disciplinares (que envolvem a matéria a ser ensinada); saberes curriculares (que envolvem o programa a ser desenvolvido); saberes das Ciências da Educação (saberes amplos, normalmente adquiridos nos cursos superiores de graduação ou na própria profissão, que são fundamentais sobre a escola, sua conexão com a sociedade e com os indivíduos que a frequentam); saberes da tradição pedagógica (representações socialmente elaboradas sobre o ofício docente, com base no que se vivencia e se faz nas escolas, na forma como o ensino se manifesta, historicamente, na sociedade); saberes experienciais (construídos pelas vivências individuais sobre o trabalho, sedimentando-se como um repertório particular) e saberes da ação pedagógica (inclui-se, aqui, todo saber experiencial 
que é compartilhado com o público, bem como colocado sob o crivo crítico das pesquisas educacionais, tornando-se saber legitimado por essa instância adicional).

Tendo como foco mais abrangente a realização de uma revisão da literatura sobre sequências didáticas (SD) e práticas pedagógicas, o conteúdo resultante deste artigo deve expressar certos saberes da ação pedagógica que, ao serem revisitados e discutidos, podem ser úteis a um número crescente de profissionais do ensino. A revisão inclui investigações/ trabalhos validados pela área acadêmica conhecida como Didática das Ciências (Ensino de Ciências ou Ensino de Ciências Naturais), sendo que esta, segundo Schnetzler (2002, p. 15), "é marcada pela especificidade do conhecimento científico, que está na raiz dos problemas de ensino e de aprendizagem investigados, implicando pesquisas sobre métodos didáticos mais adequados ao ensino daquele conhecimento".

No Brasil, essa área de estudos é representada, em boa parte, por docentes e pesquisadores que se reúnem no âmbito da Associação Brasileira de Pesquisa em Educação em Ciências (ABRAPEC), principalmente através do evento conhecido como Encontro Nacional de Pesquisa em Educação em Ciências (ENPEC), que ocorre a cada dois anos, desde sua primeira edição, no ano de 1997. O termo Educação em Ciências tem um caráter mais abrangente, que engloba o campo conhecido como Didática das Ciências e/ou Ensino de Ciências. Nesse sentido, este trabalho busca responder à seguinte questão de pesquisa: qual é o perfil geral da produção acadêmica brasileira envolvendo os temas SD e práticas pedagógicas, na última década (2010-2020), no âmbito do ENPEC? Acrescenta-se que, no cenário acadêmico mencionado, as atas do ENPEC são fontes muito apropriadas por pesquisas que objetivam revisar a literatura pertinente, obtendo-se uma visão global da produção nacional (DELIZOICOV; SLONGO; LORENZETTI, 2013).

O tema SD foi adotado, concebendo-se que: essa expressão pode designar qualquer conjunto de atividades dispostas, de modo planejado, "para a realização de certos objetivos educacionais, que têm um princípio e um fim conhecidos tanto pelos professores como pelos alunos" (ZABALA, 1998, p.18); estudos dessa natureza podem colaborar com o desenvolvimento do trabalho docente crítico, tendo-se em vista as proposições da Base Nacional Comum Curricular (BRASIL, 2017). Com sentido correlato, o termo "unidade didática" (UD) também está presente na literatura educacional (NÉRICI; 1992; PILETTI, 1997), sendo que este pode explicitar todo corpo organizado de atividades pedagógicas elaboradas com o intuito de que sejam ensinados aspectos de determinada disciplina, matéria, experiência ou situação. Nessa concepção, os conteúdos a serem trabalhados, no âmbito dos currículos escolares, são divididos em UD variadas.

Encontra-se, ainda, o termo "unidade de aprendizagem" (UA), sendo utilizado quando se quer discriminar todo conjunto de atividades que: trate de um tema específico, com abertura para movimentos interdisciplinares; possibilite que os sujeitos problematizem o conhecimento e dialoguem sobre suas vivências; viabilize movimentos investigativos e de reconstrução do conhecimento, bem como possibilite o desenvolvimento de conteúdos atitudinais e procedimentais; acentue o protagonismo discente por meio da leitura e da escrita, concebendo tais ações como indispensáveis para a aprendizagem (FRESCHI; RAMOS, 2009). A expressão "unidade temática" (UT), por sua vez, nomina qualquer bloco de atividades escolares elaborado por um ou mais docentes, que objetivem o ensino e a aprendizagem por meio da abordagem de temas que possuam conexão com o contexto da sociedade, considerando-se os diferentes níveis de análise e interferentes da vida dos sujeitos, contemplando-se aspectos científicos, históricos, sociais, tecnológicos, industriais, ambientais, dentre outros (SANTOS, F. M. T., 2007). 
O termo "material didático" (MD), por outro lado, admite uma interpretação mais abrangente, quando comparado às expressões citadas anteriormente, sendo que este pode ser entendido como qualquer recurso (meio ou dispositivo) que torne possível o aprendizado de grupos de estudantes, o qual faz parte do trabalho de todo professor, sendo indispensável o aprendizado que se refere ao seu uso (LIBÂNEO, 2013; PILETTI, 1997; ZABALA, 1998). Infere-se, a partir dessas definições, que SD, UD, UA e UT podem ser interpretados como modelos de MD referenciados na literatura educacional (que apresentam aproximações em termos estruturais e no que tange às próprias definições), os quais todo professor de Ciências Naturais pode/deve adotar, no contexto de seu trabalho. Sendo assim, as expressões mencionadas serão consideradas nesta investigação (MD, SD, UD, UA, UT).

Partindo-se de tais elementos, o escopo deste trabalho inclui: identificar características gerais da produção acadêmica com os requisitos citados; determinar a abrangência de trabalhos que apresentam, efetivamente, SD (MD/ UD/ UA/ UT) que foram desdobradas em práticas pedagógicas desenvolvidas na Educação Básica (de Ciências Naturais, de Química, de Física e/ou de Biologia); categorizar as práticas pedagógicas identificadas, à luz dos modelos pedagógicos típicos dessa área acadêmica; traçar tendências gerais e desafios para o campo da pesquisa em Ensino de Ciências Naturais, compreendendo-se a relevância da produção acadêmica investigada, no âmbito dos saberes da ação pedagógica dos docentes correlacionados.

\section{Modelos pedagógicos}

Nesta pesquisa, um dos principais pontos a serem revisados diz respeito às abordagens pedagógicas propostas em cada trabalho encontrado, no que se refere ao ensino de Ciências Naturais (FERNANDES, 2015). Menciona-se, aqui, que há certa multiplicidade de descritores encontrados para designar essas abordagens. Há autores que partem de um ponto de vista didático mais generalista (MIZUKAMI, 1986; LIBÂNEO, 2014), enquanto que outros aprofundam modelos específicos da área de Didática das Ciências (PORLÁN; MARTÍN-DEL POZO, 1996; POZO; CRESPO, 2009; FERNANDES, 2015). Nesse sentido, os termos encontrados na literatura, que serão discutidos nos parágrafos abaixo, são os seguintes: modelos pedagógicos, tendências pedagógicas, abordagens de ensino, modelos didáticos e enfoques para o ensino.

Libâneo (2014) descreve que as “tendências pedagógicas", no Brasil, podem ser liberais ou progressistas, sendo que as tendências tradicional, renovada progressivista, renovada nãodiretiva e tecnicista ficam no primeiro grupo, enquanto que, no segundo grupo, aparecem as tendências libertadora, libertária e crítico-social dos conteúdos. Mizukami (1986), por sua vez, descreve cinco "abordagens de ensino" possíveis: tradicional, comportamentalista, humanista, cognitivista e sociocultural.

Porlán e Martín-Del Pozo (1996), citados por Guimarães, Echeverría e Moraes (2006), fazem a proposição de quatro "modelos didáticos", quais sejam: tradicional, tecnológico, espontaneísta-ativista e investigativo. Pozo e Crespo (2009), por outro lado, interpretam que as Ciências Naturais, na sala de aula, podem ser pensadas com base em seis diferentes "enfoques para o ensino": tradicional; por descoberta; expositivo; por conflito cognitivo; pela pesquisa; por contraste de modelos.

Neste artigo, foi apropriada a classificação citada por Fernandes (2015) e que está presente em outros trabalhos, com foco correlato (FAHL, 2003; FERNANDES; MEGIDNETO, 2012, 2015; PUGLIESE; FERNANDES, 2017), os quais manifestam a proposição de 
cinco "modelos pedagógicos" para o ensino de Ciências Naturais: tradicional, da redescoberta, tecnicista, construtivista, Ciência-Tecnologia-Sociedade (CTS) e sociocultural. Adota-se, com isso, a seguinte perspectiva teórica:

\begin{abstract}
Modelos Pedagógicos são formulações de quadros interpretativos baseados em pressupostos teóricos utilizados para explicar ou exemplificar as ideias pedagógicas e servem de referência e parâmetro para se entender, reproduzir, controlar e/ou avaliar a prática pedagógica, entendida como uma parte do fenômeno educativo (FERNANDES, 2015, p. 27).
\end{abstract}

Neste parágrafo e nos próximos, serão explicitadas as características de cada modelo pedagógico, adotando-se os trabalhos citados como referência teórica (FAHL, 2003; FERNANDES, 2015; FERNANDES; MEGID-NETO, 2012, 2015; PUGLIESE; FERNANDES, 2017). O modelo pedagógico tradicional concebe que o professor expõe e transmite o conteúdo, sendo o centro do processo, enquanto que o estudante deve encaixar-se na dinâmica da memorização e da reprodução de informações (a maior quantidade possível de informações deve ser transmitida). Nesse modelo, a relação docente-discente é vertical, a disciplina escolar (que exige silêncio) é a base para a dinâmica de trabalho. Trata-se de um modelo que se expande, no contexto educacional, com objetivo de educar os filhos das elites, tendo grande alcance até os anos 1950, mas muito presente, ainda, no contexto atual das escolas.

O modelo pedagógico tecnicista baseia-se na instrução programada, com apoio indispensável de diferentes tecnologias da informação e comunicação (TIC), bem como apresenta embasamento teórico de matiz comportamentalista. Nesse modelo, o professor assume papel secundário, devendo aplicar atividades que possuem sequência previamente estabelecida (por outras instâncias curriculares), característica que, em tese, garantiria a recepção efetiva da informação. Na perspectiva tecnicista, que teve presença marcante nos anos 1970 e ressurgiu, com nova roupagem tecnológica, a partir dos anos 2000, a escola cumpre o papel de preparar os futuros ingressantes no mercado de trabalho, sendo que estes devem aprender a responder adequadamente às demandas que são solicitadas pelo setor mencionado (comportamento desejado).

O modelo pedagógico da redescoberta enfatiza o desenvolvimento de aulas que são baseadas em experimentação alicerçada em roteiros rígidos e fechados, objetivando-se a simulação do método científico por parte dos discentes, movimento que denota a necessidade de controle das ações e, em tese, seria suficiente para que os sujeitos redescobrissem os conhecimentos científicos, sua lógica e seus conceitos. Esse modelo teve grande repercussão no Brasil, nos anos 1960, sendo pensado para uma escola que dava centralidade à transmissão do conhecimento, com o professor assumindo um papel de menor importância, basicamente aplicando os roteiros experimentais que eram fornecidos pelos sistemas de ensino.

O modelo pedagógico construtivista coloca o aluno como o sujeito de maior protagonismo no processo de ensino e aprendizagem, sendo que este atua construindo conhecimento (novas estruturas cognitivas), enquanto que o professor assume a função mediadora das atividades, que envolvem jogos, resolução de problemas e investigações que são desenvolvidas de forma individual e coletiva. Esse modelo, calcado na motivação de cada sujeito e no envolvimento deste na atividade de aprender/conhecer, foi apropriado nos anos 1980, no cenário brasileiro, ganhando envergadura acadêmica e nos currículos oficiais, ainda que não se apresente como modelo preponderante nas práticas escolares contemporâneas (ainda assim, permanece tendo importância destacada no contexto educacional). 
O modelo CTS acentua a necessidade de a instituição escolar formar o cidadão que seja consciente das relações do conhecimento científico com a sociedade, a tecnologia, o ambiente e demais fatores que estão presentes na realidade dos estudantes, ou seja, nessa perspectiva não basta aprender bem o conteúdo escolar, é preciso que este assuma relevância no contato do sujeito com sua realidade (o conhecimento adquirido se presta à atuação e à crítica responsáveis). Aqui, o papel do professor é de mediar reflexões a serem construídas, enfatizando atividades ecléticas, normalmente explorando jogos, resolução de problemas e atividades em grupo, dentre outras. No Brasil, esse movimento tem maior influência curricular a partir dos anos 1990, sendo amplamente abordado no ambiente acadêmico brasileiro, ainda hoje, mas não tendo a mesma frequência nas salas de aula da Educação Básica.

O modelo sociocultural concebe que a escola tem o papel de dar vazão às necessidades das classes populares, no sentido de buscar a compreensão das opressões sociais, culturais e econômicas que decorrem da organização da sociedade. Busca-se sublinhar o papel político dos sujeitos envolvidos, professor e estudantes, no sentido de buscar que os processos educacionais não se limitem aos conteúdos do currículo oficial ou da disciplina, mas que possibilitem o aprendizado de modos de ser e estar no mundo, que proporcionem a emancipação dos sujeitos, fazendo-se emergir os valores humanos, nas relações que permeiam a realidade das comunidades envolvidas. Esse modelo, apesar de ser muito discutido nos círculos profissionais do magistério, principalmente por sua vinculação histórica com Paulo Freire, não tem desdobramentos curriculares consideráveis no cenário nacional, bem como tem reduzida frequência nas redes de ensino, tanto públicas, quanto privadas (FERNANDES; MEGIDNETO, 2012). O modelo desenvolve-se, sobretudo, no diálogo entre os sujeitos, no desenvolvimento de projetos e solução de problemas, sempre visando à intervenção na realidade do estudante, havendo uma relação de horizontalidade e rejeitando-se a perspectiva bancária do modelo tradicional hegemônico.

Devido à complexidade de que seja fixada qualquer classificação envolvendo as abordagens pedagógicas, cabe a observação de que estas: não possuem limites rígidos; podem, inclusive, manifestar-se de modo misto nas aulas de um mesmo professor, já que "não aparecem em sua forma pura, nem sempre são mutuamente exclusivas, nem conseguem captar toda a riqueza da prática concreta" (LIBÂNEO, 2014, p. 21). As categorias criadas no âmbito das abordagens pedagógicas prestam-se, em maior grau, para análise teórica sobre o que é feito na sala de aula, procedimento que pode ser realizado por qualquer professor/ pesquisador que esteja investigando o desenvolvimento do trabalho que envolve o ensino de qualquer área do saber (PUGLIESE; FERNANDES, 2017). Na próxima seção, será explicitada a metodologia de pesquisa adotada neste trabalho.

\section{Metodologia}

Propõe-se, neste trabalho, um movimento de revisão da literatura envolvendo a área de Didática das Ciências, considerando-se que este permite "localizar, analisar, sintetizar e interpretar a investigação prévia" (BENTO, 2012, p. 1) sobre determinado tema que seja relevante, em determinado campo do saber. Conforme o autor mencionado, estudos com essa natureza permitem que seja analisada a produção bibliográfica antecedente, de maneira detalhada, o que viabiliza a construção de uma visão que sintetiza o estado de conhecimento relacionado a certo objeto de estudo da comunidade científica. Ressalta-se que os procedimentos metodológicos, aqui adotados, são baseados em trabalhos da literatura educacional (BENTO, 2012; MARCELO; FONSECA, 2019; MIRANDA; MARTINS; CASTRO, 2018). 
Como primeiro procedimento de pesquisa, realizou-se a determinação das palavraschave conectadas à temática que se buscava revisar: MD, UD, UA, UT e SD (na busca, foram utilizadas as palavras por extenso, bem como as variações no singular e no plural). Essa definição teve como eixo norteador os estudos prévios dos autores deste artigo, que englobaram a leitura de diferentes referências do campo educacional, que abordam a organização de atividades pedagógicas na sala de aula (FRESCHI; RAMOS, 2009; NÉRICI, 1992; PILETTI, 1997; ZABALA, 1998; LIBÂNEO, 2014; SANTOS, F. M. T., 2007). O segundo procedimento de pesquisa foi caracterizado pelo estabelecimento do universo de trabalhos a ser revisado: atas das edições do ENPEC da última década, o que compreende os eventos que ocorreram nos anos de 2011, 2013, 2015, 2017 e 2019. As atas foram acessadas a partir do sítio eletrônico da ABRAPEC (2021).

O terceiro procedimento de pesquisa realizou-se pela utilização dos mecanismos de busca acessíveis para as atas disponíveis no sítio eletrônico citado, de modo que as palavraschave de interesse deste artigo foram utilizadas como descritores a serem buscados nos títulos dos trabalhos, bem como nas palavras-chave que os descreviam. $\mathrm{O}$ quarto procedimento de pesquisa permitiu a elaboração de uma base de dados sistematizados que diziam respeito aos trabalhos que passaram a compor a amostra a ser analisada. Os arquivos eletrônicos da pesquisa, sob a forma de planilhas, continham as seguintes informações organizadas, relacionadas a cada trabalho: título; edição do ENPEC em que foi encontrado; descritor através do qual foi selecionado; resumo; palavras-chave próprias; identificação dos autores. Também foram arquivados os textos integrais dos trabalhos (formato "pdf").

O quinto procedimento de pesquisa manifestou-se através do ordenamento coerente desse conjunto de dados, culminando em uma primeira sistematização analítica, que buscou elucidar o número de trabalhos da amostra com base nos seguintes critérios: a) por ano/edição do evento; b) por número de autores; c) por instituição de origem dos autores; d) por origem geográfica/ estado da federação brasileira (das instituições dos autores); e) por área de conhecimento; f) por nível de ensino (se discriminado). Esse movimento analítico, ainda que inicial, tornou possível a constituição de um quadro expositivo geral da produção acadêmica, no âmbito do ENPEC e dos objetos de interesse deste artigo.

O sexto e o sétimo procedimentos de pesquisa fizeram uso da análise de conteúdo dos textos dos trabalhos da amostra, processo que pode ser interpretado como "um conjunto de técnicas de análise das comunicações que utiliza procedimentos sistemáticos e objetivos de descrição do conteúdo das mensagens", tornando exequível "a inferência de conhecimentos relativos às condições de produção (ou, eventualmente, de recepção), inferência esta que recorre a indicadores (quantitativos ou não)" (BARDIN, 2010, p.40). Os dados analisados por essa via foram categorizados, ou seja, realizou-se a "classificação de elementos constitutivos de um conjunto, por diferenciação seguida de um reagrupamento baseado em analogias, a partir de critérios definidos" (FRANCO, 2008, p.59).

No sexto procedimento de pesquisa, por meio da análise de conteúdo (BARDIN, 2010) das palavras-chave e dos resumos dos trabalhos da amostra, foi realizada a categorização destes, buscando-se identificar o foco temático explorado e/ou os objetivos atinentes a cada trabalho. Obtiveram-se, nessa etapa, as seguintes categorias emergentes: formação de professores (envolvendo propostas de intervenção e de estudos que centram a atenção sobre os efeitos e objetivos da formação inicial ou continuada de docentes); revisão de textos (diz respeito a trabalhos que buscam revisar a produção acadêmica/ artigos ou revisar amostras de propostas/ textos didáticos de Ciências Naturais); visões dos sujeitos (engloba trabalhos que focalizam o pensamento dos sujeitos, sejam docentes ou discentes, sobre temas diversos, relacionados ao trabalho desenvolvido nas salas de aula ou com impacto no cenário educacional); currículos e 
programas (integra trabalhos que procuram aprofundar os cenários educacionais decorrentes de estruturas ou programas curriculares determinados); recursos didáticos (incorpora trabalhos que buscam descrever o desenvolvimento de diferentes ferramentas/ propostas/ MD para aulas de Ciências Naturais, com a condição de que os textos não abordem a aplicação das propostas em contextos escolares reais); práticas pedagógicas (congrega trabalhos que explicitam o desenvolvimento efetivo de propostas didáticas em aulas de Ciências Naturais, em diferentes níveis educacionais); outros (congrega trabalhos que não foram incluídos nas demais categorias, devido a suas características específicas).

O sétimo procedimento de pesquisa foi realizado exclusivamente com os trabalhos da amostra que, tendo passado pela categorização do sexto procedimento/ anterior, contemplavam plena e especificamente os critérios determinados para o escopo deste artigo, quais sejam: i. trabalhos que descrevem práticas pedagógicas desenvolvidas, de maneira efetiva, em aulas de Ciências Naturais (podendo envolver, por extensão, as áreas de Química, Física e/ou Biologia); ii. o contexto escolar de desenvolvimento das atividades as quais cada trabalho aborda deve pertencer à Educação Básica. Nesse sentido, o sétimo procedimento de pesquisa representou, em primeiro lugar, a exclusão de todos os trabalhos presentes nas categorias formação de professores, currículos e programas, revisão de textos, visões dos sujeitos, recursos didáticos e outros, bem como a exclusão dos trabalhos da categoria práticas pedagógicas que diziam respeito à Educação Superior. Esse processo, que impactou na redução da amostra a ser estudada no sétimo procedimento de pesquisa, possibilitou o refinamento da revisão da literatura que foi realizada.

No decorrer do sétimo procedimento de pesquisa, procedeu-se com a leitura integral do texto de cada trabalho da amostra refinada, obtida pelo processo mencionado no parágrafo anterior, com o propósito de que ocorresse a investigação acerca das seguintes categorias de análise (BARDIN, 2010): i. modelo pedagógico atinente às propostas presentes nos trabalhos (utilizando-se as seguintes subcategorias pré-determinadas: modelo tradicional, modelo tecnicista, modelo da redescoberta, modelo construtivista, modelo CTS e modelo sociocultural); ii. referências teóricas que fundamentam os trabalhos (emergentes da amostra); iii. conteúdos privilegiados nos processos de avaliação da aprendizagem (subcategorias prédeterminadas: conteúdos conceituais, conteúdos procedimentais e/ ou conteúdos atitudinais); iv. dinâmica da relação docente-discentes (subcategorias pré-determinadas: horizontal/ vertical); v. estratégias de ensino desenvolvidas (emergentes da amostra); vi. nível e/ou modalidade da Educação Básica nas quais são desenvolvidas as práticas pedagógicas; vii. temas contextuais possivelmente abordados. O conjunto de categorias de análise mencionadas, com base no corpus de trabalhos que foram considerados, possibilitou a elaboração de inferências fundamentadas nos referenciais da área de Ensino de Ciências. A próxima seção deste artigo vai explorar os resultados que decorrem do desenvolvimento da metodologia de pesquisa ora descrita.

\section{Resultados e discussão}

Como resultado do quinto procedimento de pesquisa, foram obtidos 137 trabalhos com as palavras-chave adotadas nas buscas, quais sejam: $\mathrm{SD}(\mathrm{N}=99$ trabalhos); $\mathrm{MD}(\mathrm{N}=27$ trabalhos); UA ( $\mathrm{N}=2$ trabalhos); UD ( $\mathrm{N}=9$ trabalhos). Não houve resultados referentes à expressão UT, na amostra em tela. Avaliando-se os resultados coletados por edição do ENPEC (Figura 1), destacaram-se quantitativamente as edições de 2015 e de 2017 (somadas, estas englobam a 58,3\% da amostra). Em termos gerais, pode-se inferir que a expressão SD é a mais abrangente, dentre as que foram consideradas, demonstrado sua relevância no cenário das 
pesquisas da área de Ensino de Ciências. Nessa esteira, verificou-se que o termo SD ocorreu com frequência destacada, quando considerada a amostra obtida neste artigo, por edição do ENPEC a ser cotejada (ano de 2011 - 61\% dos trabalhos; ano de $2013-71,4 \%$ dos trabalhos; ano de 2015 - 76,9\% dos trabalhos; ano de 2017 - 68,2\% dos trabalhos; ano de $2019-83,3 \%$ dos trabalhos).

Figura 1 - Número de trabalhos obtidos por edição do ENPEC e por palavra-chave.

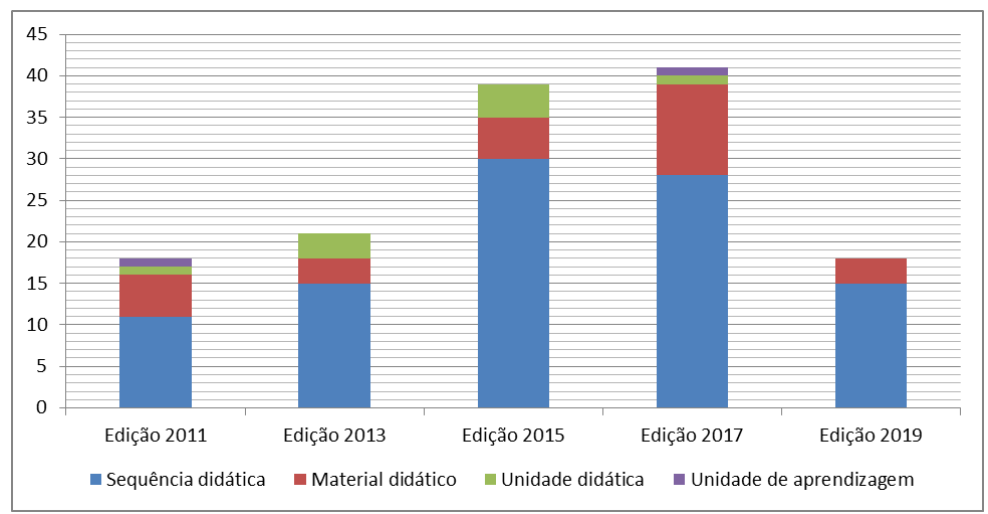

Fonte: Elaborado pelos autores (2021).

Observa-se que as frequências de trabalhos relacionados ao ensino de Física $(\mathrm{N}=23$ trabalhos) e de Química ( $\mathrm{N}=24$ trabalhos) são inferiores à frequência relacionada ao ensino de Biologia ( $\mathrm{N}=49$ trabalhos). $\mathrm{O}$ ensino de Ciências Naturais $(\mathrm{N}=41$ artigos) também possui destaque quantitativo na amostra, sendo considerados, nessa categoria, todos os trabalhos que abordam o ensino de Ciências Naturais no âmbito do Ensino Fundamental, ou trabalhos que resultam do movimento interdisciplinar entre as áreas correlacionadas (Química, Física e Biologia), independentemente do nível educacional. Tais constatações, em certo aspecto, não convergem com o que foi descrito nas revisões de Carvalho, Oliveira e Rezende (2009) e de Delizoicov, Slongo e Lorenzetti (2013), para a produção acadêmica geral, na área de Educação em Ciências, tendo-se em vista que os autores citados relataram maiores frequências de trabalhos para o ensino de Física. Desse modo, supõe-se que as diferenças citadas, no âmbito deste artigo, tenham relação com as especificidades dos termos de busca adotados/ da temática desta pesquisa, das fontes ou da série histórica revisada.

No que concerne ao nível educacional que era (possivelmente) enfocado por cada produção acadêmica, obteve-se o seguinte: há maior frequência de trabalhos direcionados ao Ensino Médio ( $\mathrm{N}=48$ trabalhos) e à Educação Superior $(\mathrm{N}=41$ trabalhos), com menor ocorrência de propostas para o Ensino Fundamental ( $\mathrm{N}=32$ artigos). Além disso, foram obtidas propostas mistas, que envolveram diferentes níveis (Ensino Fundamental/ Ensino Médio e Ensino Médio/ Educação Superior; $N=2$ trabalhos), bem como foram constatadas algumas produções acadêmicas que não especificaram o nível educacional ao qual se destinavam ( $\mathrm{N}=$ 14 trabalhos). Em relação à predominância da produção acadêmica destinada ao Ensino Médio e à representatividade inexistente da Educação Infantil, os resultados apresentados convergem com o levantamento de Delizoicov, Slongo e Lorenzetti (2013). Por outro lado, no estudo citado, há maior proximidade entre as frequências relacionadas ao Ensino Fundamental e à Educação Superior, quando comparadas com o resultado que foi obtido, proporcionalmente, no presente artigo. 
Também foi investigada a frequência relacionada à organização acadêmica e à categoria administrativa da instituição à qual a autoria de cada trabalho é afiliada, sejam vínculos profissionais ou estudantis (Tabela 1). Verifica-se que há prevalência das instituições de Educação Superior (IES) públicas, vinculadas aos autores de 94,1\% dos trabalhos analisados, com proeminente participação de Universidades Federais $(68,1 \%)$ e Universidades Estaduais (27,7\%), incluindo-se casos em que há parcerias entre diferentes instituições. Revela-se, ainda, que além da ínfima frequência de trabalhos com autoria vinculada a Escolas de Educação Básica $(5,8 \%)$ e a Universidades Privadas $(5,1 \%)$, os Institutos Federais também figuram no cenário em tela (abarcando 13,8\% dos trabalhos), o que pode ser considerado um dado positivo, ponderando-se que a expansão dessas instituições, no contexto educacional brasileiro, veio a ocorrer apenas na última década (ZACARIA; REBEQUE; LIMA, 2020). Destacam-se, em termos de frequência/ instituição, a Universidade de São Paulo-USP (N= 24 trabalhos), a Universidade Federal Rural de Pernambuco-UFRPE ( $N=10$ trabalhos) e a Universidade Federal da Bahia-UFBA (N=9 trabalhos). De um modo geral, percebem-se similaridades desse conjunto de dados com o que é relatado na literatura da área de Educação em Ciências (DELIZOICOV; SLONGO; LORENZETTI, 2013), principalmente quanto ao alcance expressivo das instituições públicas/ produtividade limitada das IES privadas, à pequena participação de autores vinculados a escolas e à relevância quantitativa da USP, na amostra.

Tabela 1 - Número de trabalhos por categoria administrativa e organização acadêmica

\begin{tabular}{l|l}
\hline Caracterização das instituições dos autores & Número de trabalhos \\
\hline Universidade Federal & 68 \\
Universidade Estadual & 20 \\
Instituto Federal / Centro Federal de Educação Tecnológica & 10 \\
Universidade Privada & 4 \\
Fundação & 3 \\
Escola de Educação Básica & 1 \\
Parceria: Universidade Federal e Universidade Estadual & 13 \\
Parceria: Universidade Estadual e Escola de Educação Básica & 4 \\
Parceria: Universidade Federal e Instituto Federal & 7 \\
Parceria: Universidade Federal e Universidade Privada & 3 \\
Parceria: Universidade Federal e Escola de Educação Básica & 2 \\
Parceria: Universidade Estadual e Instituto Federal & 1 \\
Parceria: Universidade Federal/ Instituto Federal e Escola de Educação Básica & 1 \\
Total & 137 \\
\hline
\end{tabular}

Fonte: Elaborado pelos autores (2021).

Sobre a localização geográfica dos trabalhos da amostra obtida (Figura 2), que foi determinada pelas instituições aos quais os autores são vinculados, observa-se a participação das cinco regiões brasileiras: Sul (com 29 trabalhos); Sudeste (com 66 trabalhos); Nordeste (com 35 trabalhos); Centro-Oeste (com 9 trabalhos) e Norte (com 7 trabalhos). Os estados da federação brasileira com maior presença proporcional foram São Paulo, Paraná, Minas Gerais e Bahia, sendo que, em conjunto, estes representam 60,5\% da amostra, com relação ao critério mencionado. Esses resultados possuem similaridade relativa ao que foi descrito na revisão de Delizoicov, Slongo e Lorenzetti (2013): a prevalência do estado de São Paulo e a participação 


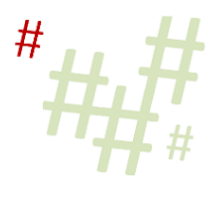

destacada do estado de Minas Gerais foram igualmente observadas, mas os autores citados obtiveram resultados mais expressivos quanto aos estados do Rio Grande do Sul e de Santa Catarina, comparando-se com o que foi constatado no presente artigo.

Figura 2 - Número de trabalhos obtidos por estado da federação brasileira.

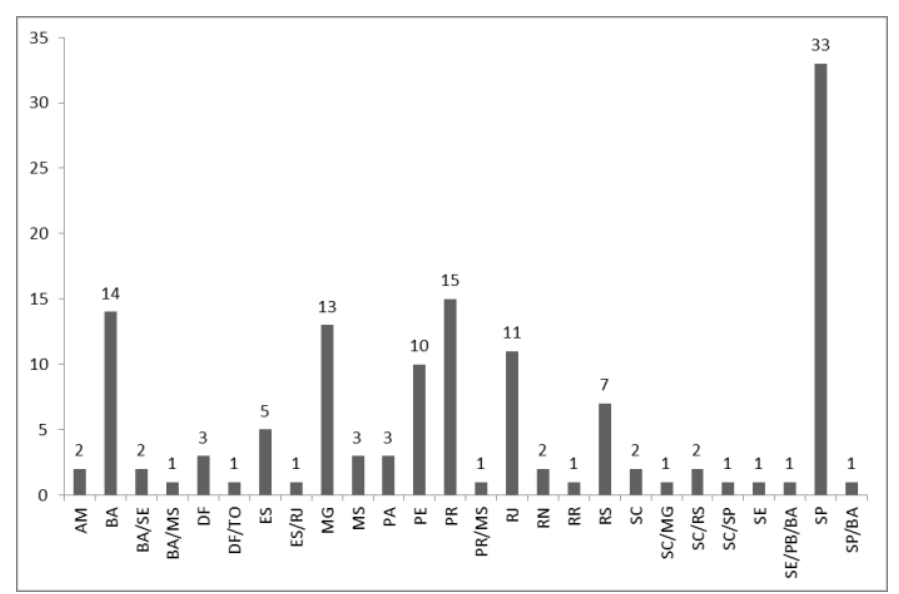

Fonte: Elaborado pelos autores (2021).

Nota: As siglas usadas na figura designam os estados brasileiros.

O número de autores por trabalho da amostra foi outro elemento investigado, já que este pode indicar o grau de estabelecimento de parcerias na comunidade acadêmica de certa área do conhecimento (CARVALHO; OLIVEIRA; REZENDE, 2009). A síntese quantitativa sobre esse quesito, concernente à revisão ora apresentada, é a seguinte: autoria individual $(\mathrm{N}=3$ trabalhos); autoria dupla ( $\mathrm{N}=66$ trabalhos); autoria tripla ( $\mathrm{N}=34$ trabalhos); autoria quádrupla $(\mathrm{N}=24$ trabalhos); autoria quíntupla $(\mathrm{N}=10$ trabalhos). Confirma-se, assim, a tendência observada na literatura da área de Educação em Ciências, a qual é caracterizada por publicações com múltiplos autores, especialmente autorias duplas e triplas (CARVALHO; OLIVEIRA; REZENDE, 2009).

A partir deste e nos próximos parágrafos desta seção, serão explorados os resultados que foram obtidos no sexto e no sétimo procedimentos de pesquisa. Os trabalhos foram categorizados segundo os objetivos de pesquisa que apresentavam, evidenciando-se os seguintes perfis temáticos: formação de professores ( $\mathrm{N}=16$ trabalhos); revisão de textos $(\mathrm{N}=$ 12 trabalhos); visões dos sujeitos $(\mathrm{N}=2$ trabalhos); outros $(\mathrm{N}=2$ trabalhos); currículos e programas $(\mathrm{N}=4$ trabalhos); recursos didáticos $(\mathrm{N}=24$ trabalhos) e práticas pedagógicas $(\mathrm{N}=$ 77 trabalhos). A prevalência quantitativa da categoria práticas pedagógicas possibilita a conclusão de que é muito presente, no cenário nacional do campo da Educação em Ciências, o desenvolvimento e a comunicação de pesquisas que aprofundam experiências de ensino efetivas, aplicadas no contexto escolar, o que denota certo nível de impacto educacional direto dessas ações acadêmicas. Salienta-se, aqui, que se adota o entendimento de que "práticas pedagógicas se referem a práticas sociais que são exercidas com a finalidade de concretizar processos pedagógicos" (FRANCO, 2016, p.536), com postura profissional docente que "dialoga com a necessidade do aluno, insiste em sua aprendizagem, acompanha seu interesse, faz questão de produzir o aprendizado, acredita que este será importante para o aluno" (FRANCO, 2016, p.541).

Dando-se sequência à investigação, procedeu-se com o refinamento da amostra de trabalhos, realizado no sétimo procedimento de pesquisa, em que foi composta uma nova 
amostra reduzida/ refinada. Nesta, foram incluídos apenas os trabalhos dispostos na categoria práticas pedagógicas que diziam respeito à Educação Básica (propostas direcionadas à Educação Superior foram desconsideradas, já que não faziam parte do escopo principal dessa etapa da revisão realizada). Os trabalhos dispostos nas demais categorias também foram excluídos, de modo que a amostra reduzida/ refinada passou a contar com o total de 69 trabalhos. As práticas pedagógicas da amostra refinada apresentam-se, em termos de frequência de nível/ modalidade educacional, com prevalência no Ensino Médio (50,7\%) e nos anos finais do Ensino Fundamental (30,4\%), havendo menor abrangência nos anos iniciais do Ensino Fundamental (10,1\%), na Educação de Jovens e Adultos/ EJA (5,8\%) e nos cursos técnicos integrados ao Ensino Médio (2,9\%).

Havendo a leitura integral dos textos da amostra refinada, deu-se prosseguimento ao estudo dos trabalhos com base nas categorias de análise mencionadas na terceira seção deste artigo, que descreveu a metodologia de pesquisa. A primeira categoria de análise a ser explorada é a que diz respeito aos modelos pedagógicos presentes nas propostas. Em relação a esse tópico, considera-se importante mencionar, com base em Fracalanza (2006) e Fernandes e Megid-Neto (2012), que nem sempre as perspectivas didáticas teóricas presentes nos discursos dos autores (nível de propósito) são coerentes com as atividades efetivamente desenvolvidas em sala de aula (nível de fato). No âmbito da amostra refinada analisada, quando divergências dessa natureza foram constatadas, deu-se validade às atividades descritas nos trabalhos, ou seja, privilegiou-se o nível de fato como critério relevante para a categorização a ser feita.

Constatou-se a seguinte distribuição, em termos dos modelos pedagógicos obtidos para a amostra refinada: modelo construtivista ( $\mathrm{N}=40$ trabalhos); modelo CTS ( $\mathrm{N}=14$ trabalhos); modelo "parcialmente" tradicional ( $\mathrm{N}=11$ trabalhos); modelo sociocultural ( $\mathrm{N}=4$ trabalhos). O modelo "parcialmente" tradicional emergiu como uma derivação analítica do modelo tradicional, tendo-se em vista que não foram constatadas, em nenhum trabalho, características que fossem puramente tradicionais (a relação docente-discente, a avaliação ou as atividades propostas desviavam-se, em todos os casos em tela, dessa classificação estrita). As análises indicam que as publicações buscam superar, em algum nível, os problemas e limitações típicas do ensino tradicional, o que tende a configurar uma asserção positiva deste estudo. Nesse quesito, percebem-se semelhanças com a literatura consultada (MARCELO; FONSECA, 2019). Outro ponto constatado é a maior frequência de trabalhos categorizados como representantes do modelo pedagógico construtivista, o que confirma a penetração deste no cenário das pesquisas sobre ensino de Ciências Naturais, conforme relatado na literatura recente da área (FERNANDES; MEGID-NETO, 2012, 2015; FERNANDES, 2015). Todavia, com base na produção desses autores, que foram mencionados, não se esperava que a frequência de trabalhos representantes do modelo pedagógico sociocultural fosse tão baixa, nem mesmo que o modelo pedagógico CTS obtivesse uma frequência relativamente alta, como foi constatado nesta investigação.

Verificou-se a existência de uma variedade de nomes de autores ( $\mathrm{N}=140$ nomes diferentes), quanto aos referenciais teóricos principais presentes em cada trabalho da amostra (cada trabalho pode ter apresentado mais de um referencial teórico principal), o que requisitou o estabelecimento de um ponto de corte (frequência mínima por autor $=3$ trabalhos), em termos dos nomes de autores a serem apresentados neste artigo (Figura 3), por exigência do limite de páginas determinado pelas normas deste periódico. Autores que exploram elementos ligados à abordagem construtivista, ou que são apropriados por pesquisas com esse viés, são os mais citados, quais sejam: Carvalho; Sasseron; Zabala; Ausubel, Vygotsky e Mortimer. Alguns apontamentos possíveis: Carvalho (2013) destaca-se por defender a abordagem investigativa para o ensino de Ciências, enquanto que Sasseron (2013), nessa esteira, enfatiza o papel 
discursivo dos sujeitos, em sala de aula, bem como a importância da alfabetização científica; Mortimer também é apropriado, principalmente, por explorar os fenômenos comunicacionais e a construção de significados, no ambiente da sala de aula de Ciências Naturais (MORTIMER; SCOTT, 2002); Zabala (1998) enfatiza a estruturação das aulas em termos da natureza da sequência didática adotada, o que conduz, em maior ou menor grau, a atividades que promovem a constituição de um ambiente baseado no estímulo à atividade mental, na comunicação, na confiança e na autonomia discente.

Figura 3 - Número de trabalhos obtidos por referencial teórico principal.

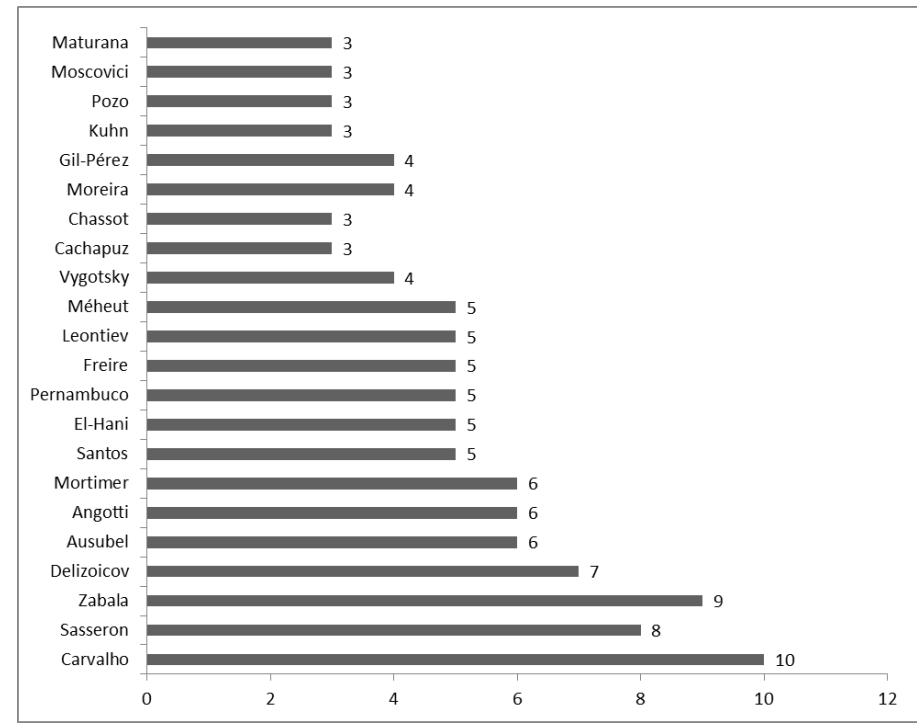

Fonte: Elaborado pelos autores (2021).

Ausubel, autor também mencionado, qualifica-se pela estruturação da chamada aprendizagem significativa, teorizando sobre o estabelecimento de pontes entre o que o sujeito já domina (conhecimento prévio) e os novos conhecimentos que este deve/ precisa aprender (AUSUBEL; NOVACK; HANESIAN, 1980). No Brasil, entre os autores que aprofundam as teorias de aprendizagem no ensino de Ciências Naturais e se inspiram nas ideias de Ausubel, ainda que não se limitem a estas, está Moreira (2011), também citado entre os referenciais da amostra estudada. Vygotsky (1985) é utilizado por oferecer subsídios teóricos relacionados aos temas da linguagem e da formação de conceitos, no contexto da aprendizagem em conexão com as interações sociais e com o estabelecimento de funções psicológicas superiores. Segundo Carretero (1997), Ausubel representa, juntamente com Piaget (1926), um grupo de referências construtivistas mais centradas no indivíduo, enquanto que Vygotsky (1985) integra um grupo distinto, que acentua o caráter social da construção do conhecimento. Além disso, sublinha-se que Piaget (1926) não foi citado na amostra cotejada, o que denota a pequena penetração das ideias desse autor no campo da Educação em Ciências, no que tange aos trabalhos que enfocam sequências didáticas e práticas pedagógicas (focos deste artigo).

Freire (1996) também está citado nos trabalhos que foram revisados, sendo valorizada a sua abordagem crítica e dialógica (bem como se acentuando a importância dos problemas relacionados à vida das classes populares), normalmente identificada com produções acadêmicas centradas nos modelos pedagógicos CTS e sociocultural. Com essa mesma perspectiva teórica, na amostra ora analisada, Delizoicov, Angotti e Pernambuco (2002) estão referenciados na amostra, ressaltando-se a estrutura didática que esses autores propõem: os 
chamados três momentos pedagógicos (problematização inicial, organização do conhecimento e aplicação do conhecimento). No rol de autores mencionados, a perspectiva crítica também é contemplada por Santos, W. L. P. (2007), este mais orientado pelas abordagens da linha CTS.

Para a categoria de análise estratégias de ensino, considerou-se que estas discriminam "as formas, os procedimentos, as ações e as atividades decorrentes do planejamento e da organização dos processos de ensino e de aprendizagem" (FARIAS et al., 2009). Os resultados obtidos apontaram a ocorrência total de 217 menções a estratégias de ensino (cada trabalho pode ter mencionado mais de uma estratégia), de modo que emergiram onze subcategorias (Quadro 1).

Quadro 1 - Estratégias de ensino presentes nas práticas pedagógicas

\begin{tabular}{|l|l|}
\hline Estratégias de Ensino - Subcategorias & $\begin{array}{l}\text { Número de } \\
\text { trabalhos }\end{array}$ \\
\hline A. Leitura, interpretação e discussão de textos (artigos; reportagens e livros). & 28 \\
\hline $\begin{array}{l}\text { B. Produção de material (textos; desenhos; folhetos; maquetes; mapas conceituais; roteiro e } \\
\text { vídeo). }\end{array}$ & 25 \\
\hline C. Experimentação com materiais de laboratórios escolares de Ciências Naturais. & 24 \\
\hline D. Atividade investigativa (resolução de problemas; uso de TIC; pesquisa; entrevistas). & 21 \\
\hline $\begin{array}{l}\text { E. Abordagem centrada em grupos (trabalhos; jogos didáticos; realização de oficinas; peça } \\
\text { teatral; seminários e gincana). }\end{array}$ & 20 \\
\hline $\begin{array}{l}\text { F. Atividades experimentais investigativas (construção de uma horta; experimento } \\
\text { investigativo; observação e descrição de figuras; estímulos táteis e sensoriais; uso de } \\
\text { fotografias e espelho em dinâmicas; utilização de simulador computacional; construção de } \\
\text { hipótese explicativa e análise; utilização de aplicativo; manuseio de dispositivos } \\
\text { fotovoltaicos; construção de vermidigestor; visitas de campo). }\end{array}$ & 16 \\
\hline $\begin{array}{l}\text { G. Aplicação de questionário (concepções prévias e/ou avaliação conceitual). } \\
\text { H. Aula expositiva e/ou dialogada (momentos expositivos e dialogados; debate; palestras; } \\
\text { apresentação eletrônica; utilização de imagens, gráficos e música). }\end{array}$ & 47 \\
\hline \begin{tabular}{l} 
I. Atividade de investigação envolvendo exibição de vídeos, filmes e documentários. \\
\hline
\end{tabular} & 20 \\
\hline
\end{tabular}

Fonte: Elaborado pelos autores (2021).

Atividades de caráter investigativo (que abarcam as subcategorias C, D, F e I), sendo experimentais ou não, representam $35,4 \%$ do total de menções às estratégias de ensino, assumindo uma posição de destaque nesse levantamento. Esse resultado não surpreende, tendose em vista que essas estratégias são muito adotadas nas aulas de caráter construtivista e CTS, prevalentes nesta revisão (FERNANDES; MEGID-NETO, 2012). No ensino de Ciências Naturais, as atividades investigativas podem ser compreendidas como aquelas que: intencionam o engajamento discente, o estabelecimento de um espaço de construção de argumentos e negociação de significados, no qual os estudantes "travam contato com fenômenos naturais, pela busca de resolução de um problema, exercitam práticas e raciocínios de comparação, análise e avaliação bastante utilizadas na prática científica" (SASSERON, 2015, p. 58); fazem com que cada estudante consiga pensar, falar, ler e escrever de forma crítica, autoral e condizente com o conhecimento sistematizado que foi trabalhado/ aprendido (CARVALHO, 2018). Em relação às atividades experimentais, sabe-se que estas podem abarcar tanto propostas mais convencionais, centradas em práticas de laboratório (subcategoria $\mathrm{C}$ ), como propostas mais abertas, variadas e flexíveis, como as descritas nas subcategorias F e I (SILVA; MACHADO; TUNES, 2013). Outra característica percebida, no perfil dos trabalhos investigados, é o número pouco expressivo de propostas que adotam as TIC como recurso de 
destaque (apenas $5,7 \%$ dos trabalhos), constatação que diverge de outros levantamentos da literatura da área de Ensino de Ciências (REIS; LEITE; LEÃO, 2017).

Destaca-se a expressiva frequência da subcategoria H (Aula expositiva e/ ou dialogada), que compreende $21,6 \%$ do total de menções às estratégias de ensino (FERNANDES; MEGIDNETO, 2012). Conforme Nérici (1992), as propostas de cunho expositivo não são necessariamente dogmáticas (pautadas na exposição de conteúdos sem contestação), pois estas apresentam o potencial de desencadear oportunidades de diálogo e participação dos estudantes, sendo que essa possibilidade foi constatada para os trabalhos contemplados na subcategoria $\mathrm{H}$. Fazendo-se uma análise dos textos completos dos 69 artigos da amostra refinada, verifica-se que em $100 \%$ destes pode ser caracterizada, com base no encadeamento das atividades desenvolvidas e relatadas, a relação horizontal docente-discente, ou seja, de abertura para dúvidas e de busca do estabelecimento de um ambiente educacional que proporciona o diálogo (FERNANDES; MEGID-NETO, 2012).

Foram aprofundados, ainda, os conteúdos considerados nos processos avaliativos dos trabalhos, concebendo-se que a avaliação "como processo mediador e formativo da aprendizagem deve, necessariamente, caminhar ao lado do processo de ensino, subsidiando as etapas que compõem a aprendizagem" (LEMOS; SÁ, 2013, p. 54). Nessa perspectiva, acreditase que seja importante a elucidação a respeito dos conteúdos conceituais (fatos, fenômenos, conceitos, leis, princípios e ideias), procedimentais (habilidades, aptidões e competências) e atitudinais (valores, interesses e regras) privilegiados, tendo-se em vista que estes tendem a fundamentar ações docentes mais direcionadas à formação humana integral (VASCONCELLOS, 2015). A análise dos textos revelou que as avaliações realizadas no desenrolar das práticas pedagógicas, de modo mais frequente, contemplam conteúdos procedimentais $(91,3 \%)$, ainda que conceituais $(69,5 \%)$ e atitudinais $(43,4 \%)$ também estejam embasando as propostas em tela. Contudo, é pouco significativo o número de trabalhos que contemplam, de forma completa/ simultânea, os três tipos de conteúdos (13\%), sendo observada maior frequência para combinações de conteúdos conceituais/ procedimentais $(47,8 \%)$ e conteúdos procedimentais/ atitudinais $(28,9 \%)$.

Práticas pedagógicas da área específica de Física aparecem em um patamar quantitativo (equivalente a $11,5 \%$ da amostra refinada) inferior à Química $(20,2 \%)$, à Biologia $(15,9 \%)$ e às Ciências Naturais $(52,1 \%)$. Esse tende a ser o diagnóstico, pelo menos, advindo da série histórica considerada e do evento privilegiado, no presente artigo. Verificou-se, ainda, que $63,7 \%$ dos trabalhos da amostra refinada adotam temas contextuais nas abordagens didáticas desenvolvidas, buscando conexões destes com os conteúdos conceituais que orientam as práticas pedagógicas respectivas (Quadro 2).

Quadro 2 - Conteúdos conceituais e temas contextuais das práticas pedagógicas

\begin{tabular}{|c|c|c|c|}
\hline Área & $\begin{array}{l}\text { Número de } \\
\text { trabalhos }\end{array}$ & $\begin{array}{l}\text { Conteúdos conceituais } \\
\text { ( } \mathrm{F}=\text { frequência de trabalhos) }\end{array}$ & $\begin{array}{l}\text { Temas contextuais } \\
\text { ( } \mathrm{F}=\text { frequência de trabalhos) }\end{array}$ \\
\hline $\begin{array}{l}\text { Ciências } \\
\text { Naturais }\end{array}$ & 35 & $\begin{array}{l}\text { Ecossistemas }(\mathrm{F}=5) ; \text { Solos, plantio e } \\
\text { vermicompostagem }(\mathrm{F}=2) ; \\
\text { Cadeia alimentar }(\mathrm{F}=2) ; \text { Insetos } \\
(\mathrm{F}=2) \text {; Alimentos }(\mathrm{F}=1) ; \text { Uso de } \\
\text { bebidas alcoólicas }(\mathrm{F}=1) ; \\
\text { Decomposição dos Materiais }(\mathrm{F}=1) \text {; } \\
\text { Meio Ambiente e resíduo }(\mathrm{F}=2) ; \\
\text { Evolução Humana }(\mathrm{F}=2) ; \mathrm{Genética} \mathrm{e} \\
\text { Sistema Reprodutor }(\mathrm{F}=3) ;\end{array}$ & $\begin{array}{l}\text { Adolescência }(\mathrm{F}=1) ; \\
\text { Alimentos }(\mathrm{F}=1) ; \\
\text { Aquecimento } \mathrm{Global}(\mathrm{F}=1) ; \\
\text { Astronomia }(\mathrm{F}=3) ; \text { Cadeia Alimentar } \\
(\mathrm{F}=1) \text {; Cidadania }(\mathrm{F}=1) ; \text { Consumo de } \\
\text { Bebidas Alcoólicas }(\mathrm{F}=1) ; \text { Corpo } \\
\text { Humano }(\mathrm{F}=1) ; \text { Dengue }(\mathrm{F}=2) ; \\
\text { Ecologia }(\mathrm{F}=4) ; \mathrm{Escravidão} \text { e cultura } \\
\text { afro-brasileira }(\mathrm{F}=1) ;\end{array}$ \\
\hline
\end{tabular}




\begin{tabular}{|c|c|c|c|}
\hline & & $\begin{array}{l}\text { Robótica }(\mathrm{F}=1) \text {; Densidade e } \\
\text { Gravidade }(\mathrm{F}=1) ; \text { Lua/Céu e Planetas } \\
(\mathrm{F}=3) \text {; Células }(\mathrm{F}=1) ; \text { Puberdade e } \\
\text { Gravidez }(\mathrm{F}=3) ; \\
\text { Biodiversidade }(\mathrm{F}=2) ; \text { Doenças } \\
\text { Transmitidas pela água }(\mathrm{F}=1) ; \\
\text { Bactérias }(\mathrm{F}=1) ; \text { Densidade }(\mathrm{F}=1) \text {. }\end{array}$ & $\begin{array}{l}\text { Filmes }(\mathrm{F}=1) \text {; Horta e Plantas } \\
\text { Medicinais }(\mathrm{F}=3) \text {; Foguetes Artesanais } \\
(\mathrm{F}=1) \text {; Lixo }(\mathrm{F}=1) \text {; } \\
\text { Meio Ambiente e Saúde }(\mathrm{F}=2) \text {; } \\
\text { Sexualidade }(\mathrm{F}=4) \text {; } \\
\text { Robótica }(\mathrm{F}=1) \text {; Ambiente }(\mathrm{F}=1) \text {. }\end{array}$ \\
\hline Química & 14 & $\begin{array}{l}\text { Misturas e propriedades físicas dos } \\
\text { materiais }(\mathrm{F}=1) \text {; Funções Orgânicas e } \\
\text { Cadeias carbônicas }(\mathrm{F}=5) \text {; Sais } \\
\text { Inorgânicos }(\mathrm{F}=1) \text {; Química Analítica } \\
(\mathrm{F}=1) \text {; Termoquímica }(\mathrm{F}=1) \text {; } \\
\text { Eletroquímica }(\mathrm{F}=2) \text {; Grandezas } \\
\text { químicas }(\mathrm{F}=1) \text {; Reações químicas } \\
(\mathrm{F}=3) \text {; Transformação de materiais } \\
(\mathrm{F}=1) \text {. }\end{array}$ & $\begin{array}{l}\text { Nutrição }(\mathrm{F}=1) ; \text { Agricultura }(\mathrm{F}=1) ; \\
\text { Corantes }(\mathrm{F}=1) ; \\
\text { Música }(\mathrm{F}=1) ; \text { Perfumes }(\mathrm{F}=2) ; \\
\text { Pesticidas }(\mathrm{F}=1) ; \\
\text { Pilhas }(\mathrm{F}=1) \text {. }\end{array}$ \\
\hline Biologia & 12 & $\begin{array}{l}\text { Síntese Proteica }(\mathrm{F}=1) ; \\
\text { Microrganismos }(\mathrm{F}=1) ; \\
\text { Biodiversidade }(\mathrm{F}=2) ; \text { Geologia e } \\
\text { evolução }(\mathrm{F}=3) ; \text { Dengue }(\mathrm{F}=1) ; \\
\text { Tipos Sanguíneos }(\mathrm{F}=1) ; \text { Bactérias } \\
(\mathrm{F}=1) \text {; Citologia }(\mathrm{F}=1) ; \text { Sistema } \\
\text { circulatório }(\mathrm{F}=1) .\end{array}$ & $\begin{array}{l}\text { Dengue }(\mathrm{F}=1) \text {; Epidemias, Câncer, } \\
\text { Clonagem, Células Tronco, } \\
\text { Reprodução Humana }(\mathrm{F}=1) ; \\
\text { Microbiologia }(\mathrm{F}=1) ; \\
\text { Sistema Sanguíneo }(\mathrm{F}=1) .\end{array}$ \\
\hline Física & 8 & $\begin{array}{l}\text { Ondulatória }(\mathrm{F}=2) \text {; Eletrostática } \\
(\mathrm{F}=1) \text {; Gravitação }(\mathrm{F}=1) \text {; } \\
\text { Luz e Cores }(\mathrm{F}=1) \text {; Nanotecnologia } \\
(\mathrm{F}=1) \text {; Refração e Ressonância }(\mathrm{F}=1) \text {; } \\
\text { Efeito fotoelétrico }(\mathrm{F}=1) \text {. }\end{array}$ & O Universo $(\mathrm{F}=1)$ \\
\hline
\end{tabular}

Fonte: Elaborado pelos autores (2021).

O trabalho pedagógico que tem o seu princípio em temas do contexto do estudante pode ser caracterizado como uma abordagem dialética do conhecimento, que parte da realidade em direção ao conhecimento científico (VASCONCELLOS, 2015), ensejando uma visão complexa da vida social (a ser problematizada em sala de aula), o que tende a convergir com os modelos pedagógicos CTS e sociocultural (FERNANDES; MEGID-NETO, 2012). Segundo Saviani (2005), a escola tem a prerrogativa de fornecer as ferramentas necessárias para a participação política consciente dos estudantes nas práticas sociais que os atravessam, o que requer o domínio da interpretação de elementos da cultura popular/ temas contextuais através das lentes especializadas do saber sistematizado.

\section{Considerações Finais}

A partir do conjunto de resultados apresentados e análises efetuadas, infere-se que este trabalho atingiu os objetivos propostos, considerando-se que foi possível a identificação de que as pesquisas envolvendo os termos $\mathrm{SD} / \mathrm{MD} / \mathrm{UD} / \mathrm{UA}$ são, majoritariamente, elaboradas por autores que atuam coletivamente, oriundos de universidades públicas da região sudeste do Brasil. As práticas pedagógicas constatadas na amostra, em maior proporção: são destinadas ao ensino de Ciências Naturais desenvolvido no Ensino Médio e/ou nos anos finais do Ensino Fundamental; abrangem aulas expositivas e dialogadas/ atividades investigativas; orientam-se 
pelo modelo pedagógico construtivista, privilegiando conteúdos conceituais e procedimentais em seus processos avaliativos, bem como utilizando temas contextuais como elementos orientadores das atividades.

No trabalho ora apresentado, os resultados obtidos trazem provocações ao campo acadêmico da Didática das Ciências, relacionadas à necessidade: de maior participação de professores, atuantes em escolas de Educação Básica, na autoria de trabalhos da literatura especializada; de maior valorização e disseminação de abordagens pedagógicas que contemplem a perspectiva centrada no modelo pedagógico sociocultural, dada a riqueza dos ideários de autores com perspectivas críticas, que estão presentes no cenário educacional nacional (FREIRE, 1996; LIBÂNEO, 2014; SAVIANI, 2005). A área acadêmica em tela precisa, ainda, dar maior visibilidade e ampliar a ocorrência de pesquisas envolvendo práticas pedagógicas voltadas aos anos iniciais do Ensino Fundamental e à Educação Infantil, que podem problematizar, por exemplo: a natureza dos conceitos científicos e a mediação didática necessária para o ensino de Ciências Naturais para crianças, em termos das estratégias e dos materiais didáticos disponíveis; a formação de docentes que atuam nesses níveis educacionais (incluindo-se o currículo da formação inicial e as propostas de formação continuada), em termos de domínio dos conteúdos científicos e tecnológicos.

Os elementos evidenciados nesta investigação podem passar a compor os saberes da ação pedagógica de diferentes docentes da Educação Básica que atuam na área de Ciências Naturais, tendo reflexo direto nas salas de aula, onde atuam esses profissionais. Os resultados obtidos também podem colaborar com práticas de formação docente, tanto nos cursos de licenciatura, quanto na pós-graduação relacionada ao Ensino de Ciências.

O contexto do biênio 2020-2021, que abrange as situações de alta complexidade decorrentes da pandemia de COVID-19, por exemplo, não foi coberto pela presente revisão, apresentando alta tendência de se estabelecer como temática motivadora de pesquisas futuras. Novos estudos específicos, envolvendo o ensino de Física, de Química ou de Biologia, por outro lado, também podem ser pensados como forma de contrapor ou confirmar os achados que foram apresentados. Ainda que os resultados ora obtidos sejam restritos à coletânea de trabalhos advinda das edições do ENPEC, estes se configuram como ponto de partida representativo e fundamentado para outras pesquisas, diálogos e debates, que expressem concordâncias e discordâncias com as análises empreendidas, tendo potencial para gerar novas reflexões sobre o contexto educacional brasileiro.

\section{Financiamento e agradecimentos}

Agradecemos ao CNPq e à PROPESQ/UFRGS pela bolsa de iniciação científica.

\section{Referências}

ABRAPEC. Sítio Eletrônico, 2021. Disponível em: http://abrapecnet.org.br/wordpress/pt/ atas-dos-enpecs/ Acesso em: 17 ago. 2021.

AUSUBEL, D. P.; NOVAK, J. D.; HANESIAN, H. Psicologia Educacional. Rio de Janeiro: Interamericana, 1980.

BARDIN, L. Análise de Conteúdo. Lisboa, Edições 70, 2010. 
BENTO, A. Como fazer uma revisão da literatura: considerações teóricas e práticas. Revista JA - Associação Académica da Universidade da Madeira, Funchal, n. 65, v. 7, p. 42-44, 2012.

BRASIL. Ministério da Educação. Base Nacional Comum Curricular. Brasília, 2017.

CARRETERO, M. Construtivismo e Educação. Porto Alegre: Artes Médicas, 1997.

CARVALHO, A. M. P. O ensino de ciências e a proposição de sequências de ensino investigativas. In: CARVALHO, A. M. P. (Org.). Ensino de ciências por investigação: condições para implementação em sala de aula. São Paulo: Cengage Learning, 2013.

CARVALHO, A. M. P. de. Fundamentos Teóricos e Metodológicos do Ensino por Investigação. Revista Brasileira de Pesquisa em Educação em Ciências, [S. l.], v. 18, n. 3, p. 765-794, 2018.

CARVALHO, R. C.; OLIVEIRA, I.; REZENDE, F. Tendências da pesquisa na área de educação em ciências: uma análise preliminar da publicação da ABRAPEC. In: VII ENCONTRO NACIONAL DE PESQUISA EM EDUCAÇÃO EM CIÊNCIAS - VII ENPEC, Belo Horizonte. Anais [...]. Belo Horizonte, 2009.

DELIZOICOV, D.; ANGOTTI, J.; PERNAMBUCO, M. M. Ensino de Ciências: fundamentos e métodos. São Paulo: Cortez, 2002.

DELIZOICOV, D.; SLONGO, I. I. P.; LORENZETTI, L. Um panorama da pesquisa em educação em ciências desenvolvida no Brasil de 1997 a 2005. Revista Electrónica de Enseñanza de las Ciencias, Pontevedra, v. 12, n. 3, p. 459-480, 2013.

FAHL, D. D. Marcas do ensino escolar de Ciências presentes em Museus e Centros de Ciências. Dissertação (Mestrado em Educação), Faculdade de Educação, Universidade Estadual de Campinas, São Paulo, 2003.

FARIAS, I. M. S. de. et al. Didática e Docência: aprendendo a profissão. Brasília: Líber Livro, 2009.

FERNANDES, R. C. A.; MEGID-NETO, J. Modelos educacionais em 30 pesquisas sobre práticas pedagógicas no ensino de ciências nos anos iniciais da escolarização. Investigações em Ensino de Ciências, Porto Alegre, v. 17, n. 3, p. 641-662, 2012.

FERNANDES, R. C. A.; MEGID-NETO, J. Características e tendências das dissertações e teses brasileiras sobre práticas de ensino de ciências nos anos iniciais escolares (1972-2011). Interacções, n. 39, p. 540-551, 2015.

FERNANDES, R. C. A. Inovações pedagógicas no ensino de ciências dos anos iniciais: um estudo a partir de pesquisas acadêmicas brasileiras (1972-2012). Tese (Doutorado em Educação) - Faculdade de Educação, Universidade Estadual de Campinas, 2015. 
FRACALANZA, H. O ensino de Ciências no Brasil. In: FRACALANZA, H.; MEGIDNETO, J. (Orgs.). O livro Didático de Ciências no Brasil. Campinas: Komedi, 2006.

FRANCO, M. L. P. B. Análise de Conteúdo. 3. ed. Brasília: Líber Livro Editora, 2008.

FRANCO, M. A. R. S. Prática pedagógica e docência: um olhar a partir da epistemologia do conceito. Revista Brasileira de Estudos Pedagógicos, Brasília, v. 97, n. 247, p. 534-551, 2016.

FREIRE, P. Pedagogia da autonomia: saberes necessários à prática educativa. São Paulo: Paz e Terra, 1996.

FRESCHI, M.; RAMOS, M. G. Unidade de Aprendizagem: um processo em construção que possibilita o trânsito entre senso comum e conhecimento científico. Revista Electrónica de Enseñanza de las Ciencias, Pontevedra, v.8, n.1, p.156-170, 2009.

GAUTHIER, C. et al. Por uma teoria da Pedagogia: pesquisas sobre o saber docente. 3. ed. Ijuí: Editora Unijuí, 2013.

GUIMARÃES, G. M. A.; ECHEVERRÍA, A. R.; MORAES, I. J. Modelos didáticos no discurso de professores de ciências. Investigações em Ensino de Ciências, Porto Alegre, v.11, n.3, p.303-322, 2006.

LEMOS, P. S.; SÁ, L.P. A avaliação da aprendizagem na concepção de professores de química do ensino médio. Revista Ensaio, Belo Horizonte, v.15, n. 03, p. 53-71, 2013.

LIBÂNEO, J. C. Didática. 2. ed. São Paulo: Cortez, 2013.

LIBÂNEO, J. C. Democratização da Escola Pública: a pedagogia crítico-social dos conteúdos. 28. ed. São Paulo: Loyola, 2014.

MARCELO, M. C. A.; FONSECA, C. V. Modelos educacionais na licenciatura em Química: um estudo documental envolvendo trabalhos de conclusão de curso. Revista Profissão Docente (Online), Uberaba, v. 19, p. 1-28, 2019.

MIRANDA, N. da S.; MARTINS, L.; CASTRO, L. V. F. S. Propostas didático-pedagógicas para a Educação em Saúde: análise crítica de trabalhos publicados nos Encontros Nacionais de Pesquisa em Educação em Ciências (ENPEC). Revista Entreideias: Educação, Cultura e Sociedade, Salvador, v. 7, p. 127-150, 2018.

MIZUKAMI, M. G. N. Ensino: as abordagens do processo. São Paulo: EPU, 1986.

MOREIRA, M. A. Teorias da Aprendizagem. 2 Ed. São Paulo: Editora E.P.U, 2011.

MORTIMER, E. F.; SCOTT, P. Atividade discursiva nas salas de aula de ciências: uma ferramenta sócio-cultural para analisar e planejar o ensino. Investigações em Ensino de Ciências, Porto Alegre, v. 7, n. 3, p. 283-306, 2002.

NÉRICI, I. G. Metodologia do Ensino: uma introdução. 4. ed. São Paulo: Atlas, 1992. 
PIAGET, J. La representation du monde chez l'enfant. Paris: Alcan, 1926.

PILETTI, C. Didática Geral. São Paulo: Editora Ática, 1997.

PORLÁN, R.; MARTÍN-DEL POZO, R. Ciencia, profesores y enseñanza: unas relaciones complejas. Alambique: Didáctica de las ciencias experimentales, Barcelona, n. 8, p. 23-32, 1996.

POZO, J. I.; CRESPO, M. A. G. A aprendizagem e o ensino de ciências: do conhecimento cotidiano ao conhecimento científico. 5. ed. Porto Alegre: Artmed, 2009.

PUGLIESE, G. O.; FERNANDES, R. C. A. Identificação de modelos pedagógicos presentes nas concepções sobre ensino de ciências de professores da educação básica. In: ENCONTRO NACIONAL DE PESQUISA EM EDUCAÇÃO EM CIÊNCIAS 11.,2017, Florianópolis. Anais [...]. Florianópolis, 2017.

REIS, R. da S.; LEITE, B. S.; LEÃO, M. B. C. Apropriação das Tecnologias da Informação e Comunicação no ensino de ciências: uma revisão sistemática da última década (2007-2016).

Revista Novas Tecnologias na Educação, Porto Alegre, v. 15, n.2, p. 1-10, 2017.

SAVIANI, D. Pedagogia Histórico-crítica: primeiras aproximações. 9. ed. Campinas: Autores Associados, 2005.

SANTOS, F. M. T. dos. Unidades temáticas: produção de material didático por professores em formação inicial. Experiências em Ensino de Ciências, Porto Alegre, v. 2, n. 1, p. 01-11, 2007.

SANTOS, W.L.P. Contextualização no ensino de ciências por meio de temas CTS em uma perspectiva crítica. Ciência \& Ensino, v.1, n. esp., 2007.

SASSERON, L. H. Interações discursivas e investigação em sala de aula: o papel do professor. In: CARVALHO, A. M. P. (Org.). Ensino de ciências por investigação: condições para implementação em sala de aula. São Paulo: Cengage Learning, 2013.

SASSERON, L. H. Alfabetização científica, ensino por investigação e argumentação: relações entre ciências da natureza e escola. Ensaio Pesquisa em Educação em Ciências, Belo Horizonte, v. 17, n. esp., p. 49-67, 2015.

SCHNETZLER, R. P. A pesquisa em ensino de química no Brasil: conquistas e perspectivas. Química Nova, São Paulo, v. 25, p. 14-24, 2002.

SILVA, R. R.; MACHADO, P. F. L.; TUNES, E. Experimentar Sem Medo de Errar. In: SANTOS, W. L. P. dos; MALDANER, O. A. Ensino de Química em Foco. Ijuí: Editora Unijuí, 2010. p. 231-261.

VASCONCELLOS, C. dos S. Planejamento: Projeto de Ensino-Aprendizagem e Projeto Político-Pedagógico. 25 ed. São Paulo: Libertad, 2015. 
VEIGA, I. P. A. Ensinar: uma atividade complexa e laboriosa. In: VEIGA, I. P. A. (org.).

Lições de Didática. 5. ed. Campinas: Papirus, 2012. 160 p.

VYGOTSKY, L. S. Pensamiento y lenguaje. Buenos Aires: Plújade, 1985.

ZABALA, A. A prática educativa: como ensinar. Porto Alegre: Artmed, 1998.

ZACARIA, E. G. D. ; REBEQUE, P. V. ; LIMA, F. B. G. . Dez anos de criação dos Institutos Federais de Educação, Ciência e Tecnologia: sobre a oferta de licenciaturas nas áreas de Ciências e Matemática. \#Tear: Revista de Educação, Ciência e Tecnologia, Canoas, v. 9, p. 1, 2020.

Recebido em agosto de 2021.

Aprovado em outubro de 2021. 